\title{
Mortality and cancer morbidity in workers from an aluminium smelter with prebaked carbon anodes-part II: cancer morbidity
}

\author{
Alf Rønneberg, Aage Andersen
}

\begin{abstract}
Objective-To investigate associations between cancer incidence and exposure to coal tar pitch volatiles, asbestos, pot emissions (fluorides, sulphur dioxide), heat stress, and magnetic fields in workers from a Norwegian aluminium smelter that operated from 1914 to 1975 .
\end{abstract}

Methods-Cancer incidence between 1953 and 1991 was recorded in a cohort of 1137 men hired between 1922 and 1975. The expected number of cancer cases was calculated from incidence rates in Norwegian men. A job exposure matrix with semiquantitative exposure estimates was used to investigate associations between cumulative exposure and cancer incidence through exploring temporal relations by considering exposures only within specific time windows.

Results-A significant excess of cancer cases, 90 observed $v 59.0$ expected, was found in workers who had been employed for less than three years. No such excess was found in men with at least three years' employment, with 120 cases observed $v 129.7$ expected. In this subcohort an association was found between the incidence of bladder cancer and exposure to coal tar pitch volatiles 40 years or more before each person-year under observation, and between incidence of lung cancer and tar exposure 35-50 years before observation. An association was also found between incidence of kidney cancer and exposure to heat stress 20-35 years before observation. Conclusions-The results support previous findings that exposure to coal tar pitch volatiles in the aluminium industry has been associated with increased risk of bladder and lung cancer. They also add information about temporal relations, suggesting that exposure to tar in this smelter has acted on an early stage in the development of these cancers, followed by a latency period of $30-40$ years.

(Occup Environ Med 1995;52:250-254)

Norway, Institute of

Epidemiological

Cancer Research,

Oslo, Norway

A Rønneberg

A Andersen

Correspondence to:

Dr A Rønneberg, The

Cancer Registry of Norway,

Institute of Epidemiological

Cancer Research,

Montebello, N-0310 Oslo,

Norway.

Accepted 24 November 1994 miological studies of aluminium smelter workers have shown associations between exposure to coal tar pitch volatiles and the risk of bladder cancer ${ }^{14}$ and lung cancer. ${ }^{25}$ Some data have also suggested an increased risk of haematopoietic cancers, ${ }^{467}$ kidney cancer, ${ }^{27}$ and brain tumours, ${ }^{47}$ and increased mortality from pancreatic cancer has been reported in men who have worked in the electrolytic potrooms of such smelters. ${ }^{7}$

A study of cancer in the Norwegian aluminium industry showed excesses of bladder and lung cancers in workers from a prebake smelter that operated between 1914 and $1975 .^{89}$ Detailed work histories had been abstracted from the smelter's personnel files shortly after its closure, and an assessment of exposures has been presented in a separate paper. ${ }^{10}$ The objective of the present study was to use this information to investigate certain associations between specific exposures and cancer sites selected from evidence reviewed in a previous paper ${ }^{11}$-namely: coal tar pitch volatiles (tar) and cancers of the lung and urinary tract; asbestos and cancers of the lung and pleura; pot emissions (fluorides, sulphur dioxide, carbon monoxide, aluminium oxide) and cancers of the pancreas and lung; magnetic fields and cancers of the brain and haematopoietic tissue; heat stress and cancers of the urinary tract.

\section{Material and methods}

The investigation was designed as a cohort study of cancer incidence between 1953 and 1991. During this period the Cancer Registry of Norway gives a complete coverage of the population for cancer sites other than basal cell carcinoma of the skin. The cohort was defined as all men, hired between 1 January 1922 and the smelter's closure on 1 April 1975, who had been employed for at least six months at a time.

Table 1 shows details of the cohort. A list had been compiled of all 1721 workers

Table 1 Formation of the study

\begin{tabular}{lrlc}
\hline & \multicolumn{3}{c}{ Year of hire } \\
\cline { 3 - 4 } & All & $1912-21$ & $1922-75$ \\
\hline $\begin{array}{l}\text { Initial records (n): } \\
\text { Women }\end{array}$ & 1721 & 486 & 1235 \\
Employed < 6 months & 13 & 0 & 13 \\
$\begin{array}{l}\text { Dead or migrated before } \\
\quad 1953\end{array}$ & 16 & 3 & 13 \\
$\begin{array}{l}\text { Men satisfying initial cohort } \\
\text { definition (n) }\end{array}$ & 1602 & 417 & 1185 \\
$\begin{array}{l}\text { Lost to follow up } \\
\text { Employed before 1922 }\end{array}$ & 206 & 158 & 48 \\
$\begin{array}{c}\text { Men satisfying final cohort } \\
\text { definition (n)t }\end{array}$ & 259 & 259 & -1137 \\
\hline
\end{tabular}

*All men employed for $\geqslant 6$ months between 1914 and 1975 
included in the smelter's personnel files, containing name, date of birth, and complete work histories. The Central Bureau of Statistics provided 11 digit personal identification numbers for all men alive at the census in 1960, and the date of death or emigration for those who had died or emigrated between 1951 and 1991. Men who had died or emigrated before 1951 were identified through interviews with former employees. The final cohort included 1137 men after exclusion of 48 (4\%) whose vital status could not be ascertained. Only five of those lost to follow up had been employed after the beginning of the observation period in 1953.

Men hired before 1922 were excluded for three reasons: firstly, this period was characterised by irregular production and frequent movement of men between work areas, and work histories were lacking in detail; secondly, only 259 (62\%) could be identified of the 417 eligible men hired during this period; thirdly, those who left before 1918 had been lost from the personnel files. It was therefore assumed that the gain in cohort size by including this group would not compensate for increased exposure misclassification and selection bias.

Each cohort member was investigated for the event of cancer or death from 1 January 1953 or from the date of employment if later, and until death or 31 December 1991 for those alive at this date. Cancer cases were identified from the Cancer Registry through each cohort member's name and date of birth between 1953 and 1960 and his personal identification number after 1960. Basal cell carcinoma of the skin was not included in the analysis.

The cohort's cancer morbidity was investigated by stratified analysis that compared the observed number of cancer cases in each stratum with the expected number calculated from age specific national incidence by five year age groups for each year under observation. Standardised incidence ratios (SIRs) were calculated as the ratio between the observed and expected number, and $95 \%$ confidence intervals ( $95 \%$ CIs) were calculated by comparison with the Poisson distribution.
The intensity of exposure to coal tar pitch volatiles, asbestos, pot emissions, heat stress, and magnetic fields had been assessed on a semiquantitative scale from nil to 1.00 for all jobs in the smelter. ${ }^{10}$ Dose-response relations between specific exposures and cancers were investigated with cumulative exposure used as a surrogate for dose. This was calculated in intensity-years as the product of exposure intensity and duration summed for all jobs held at the smelter.

Duration of employment and cumulative exposure were treated as time related variables for each person-year under observation, and one person was allowed to contribute to more than one stratum in each analysis. All unexposed person-years were assigned to one stratum, and the exposed person-years were divided into one low and one high stratum that each included a roughly equal amount of person-time.

The temporal relation between exposure and cancer incidence was explored by restricting exposure to specific time windows, and only exposures received within the window were considered to be aetiologically relevant. This approach is based on the notion that the interval from the first relevant exposure to diagnosis of disease may be divided into an induction period during which sufficient exposure occurs to induce the disease, then by a latency period until the disease can be diagnosed. ${ }^{12-14}$

In the absence of evidence of the duration of the induction and latency periods, cumulative exposure was calculated within a 15 year time window that was moved five years at a time from $0-15$ years to 40 or more years before observation. This resulted in a series of nine independent analyses in which the total number of observed and expected cases was constant, but where the allocation of each person-year and cancer case to the exposure strata depended on the amount of exposure received within the time window.

Each association was tested for trend with the Poisson trend statistic (two sided). ${ }^{15}$ Due to the multiple comparisons performed for each pair of agent and disease, $P$ values were

Table 2 Observed (Obs) number of cancer cases and SIRs (95\% CIs) among 1137 male aluminium smelter workers in 1953-91, by cumulative employment

\begin{tabular}{|c|c|c|c|c|c|c|}
\hline \multirow[b]{3}{*}{ Cancer site (ICD-7 codes) } & \multicolumn{6}{|c|}{ Cumulative employment } \\
\hline & \multicolumn{3}{|c|}{$<3 y$} & \multicolumn{3}{|c|}{$\geqslant 3 y$} \\
\hline & Obs & SIR & $(95 \% C I)$ & Obs & SIR & $(95 \% C I)$ \\
\hline All sites & 90 & 1.53 & $(1 \cdot 23-1 \cdot 88)$ & 120 & 0.93 & $(0 \cdot 77-1 \cdot 11)$ \\
\hline Lip (140) & 1 & $1 \cdot 14$ & $(0 \cdot 03-6 \cdot 33)$ & 4 & $2 \cdot 07$ & $(0 \cdot 56-5 \cdot 31)$ \\
\hline Upper respiratory tract $(141,143-8,160-1)$ & 3 & 1.46 & $(0 \cdot 30-4 \cdot 28)$ & 3 & $0 \cdot 70$ & $(0 \cdot 14-2 \cdot 03)$ \\
\hline Stomach (151) & 9 & 1.55 & $(0.71-2 \cdot 94)$ & 7 & 0.54 & $(0 \cdot 22-1 \cdot 12)$ \\
\hline Colon and rectum (153-4) & 8 & 1.05 & $(0 \cdot 45-2 \cdot 06)$ & 14 & $0 \cdot 82$ & $(0 \cdot 45-1 \cdot 38)$ \\
\hline Pancreas (157) & 2 & 0.91 & $(0 \cdot 11-3 \cdot 30)$ & 4 & 0.69 & $(0 \cdot 19-1 \cdot 78)$ \\
\hline Lung (162) & 20 & $2 \cdot 65$ & $(1 \cdot 62-4 \cdot 09)$ & 19 & $1 \cdot 16$ & $(0 \cdot 70-1 \cdot 81)$ \\
\hline Prostate (177) & 16 & 1.55 & $(0 \cdot 88-2 \cdot 51)$ & 19 & 0.75 & $(0 \cdot 45-1 \cdot 17)$ \\
\hline Kidney (180) & 2 & 0.93 & $(0 \cdot 11-3 \cdot 34)$ & 6 & $1 \cdot 31$ & $(0 \cdot 48-2 \cdot 85)$ \\
\hline Bladder (181) & 5 & $1 \cdot 28$ & $(0 \cdot 42-2 \cdot 98)$ & 14 & $1 \cdot 58$ & $(0 \cdot 86-2 \cdot 65)$ \\
\hline Malignant melanoma (190) & 3 & 1.73 & $(0 \cdot 36-5 \cdot 07)$ & 5 & 1.66 & $(0 \cdot 54-3 \cdot 88)$ \\
\hline Skin (191; excluding basal cell carcinoma) & 5 & 3.09 & $(1 \cdot 00-7 \cdot 20)$ & 3 & $0 \cdot 79$ & $(0 \cdot 16-2 \cdot 30)$ \\
\hline Brain, nervous system (193) & 2 & $1 \cdot 16$ & $(0 \cdot 14-4 \cdot 18)$ & 2 & 0.63 & $(0.08-2 \cdot 29)$ \\
\hline Lymphoma (200-2) & 4 & 1.96 & $(0.53-5 \cdot 02)$ & 2 & 0.51 & $(0.06-1 \cdot 83)$ \\
\hline Multiple myeloma (203) & 2 & 1.89 & $(0 \cdot 23-6 \cdot 82)$ & 2 & $0 \cdot 84$ & $(0 \cdot 10-3 \cdot 04)$ \\
\hline Leukaemia (204) & 1 & 0.65 & $(0.02-3 \cdot 62)$ & 5 & 1.53 & $(0.50-3.57)$ \\
\hline All other sites & 7 & 1.05 & $(0 \cdot 42-2 \cdot 16)$ & 11 & $0 \cdot 85$ & $(0 \cdot 42-1 \cdot 52)$ \\
\hline
\end{tabular}


Table 3 SIRs for selected cancers in 1953-91 among 694 aluminium smelter workers with at least three years employment, by cumulative exposure to coal tar pitch volatiles

\begin{tabular}{|c|c|c|c|c|c|c|}
\hline \multirow[b]{2}{*}{ Cancer site } & \multirow{2}{*}{$\begin{array}{l}\text { Time window } \\
\text { for exposure } \\
\text { before observation } \\
(y)\end{array}$} & \multicolumn{3}{|c|}{ Cumulative exposure (intensity-y) } & \multirow{2}{*}{$\begin{array}{l}\text { Poisson } \\
\text { trend } \\
\text { statistic } \\
\left(\%^{\prime}\right)\end{array}$} & \multirow{2}{*}{$\begin{array}{l}P \text { value } \\
\text { for } \\
\text { trend }\end{array}$} \\
\hline & & $\begin{array}{l}0 \\
\operatorname{SIR}(n)\end{array}$ & $\begin{array}{l}<3 \\
\operatorname{SIR}(n)\end{array}$ & $\begin{array}{l}\geqslant 3 \\
\operatorname{SIR}(n)\end{array}$ & & \\
\hline \multicolumn{7}{|l|}{ Bladder: } \\
\hline & All & $1 \cdot 18(7)$ & $2 \cdot 42(3)$ & $2 \cdot 38(4)$ & 1.57 & 0.21 \\
\hline & $0-15$ & $1.39(11)$ & $5.00(3)$ & $0.00(0.4)$ & $0 \cdot 34$ & \\
\hline & $5-20$ & 1.45 (11) & $3.33(2)$ & $1.67(1)$ & 0.32 & \\
\hline & $10-25$ & $1.35(10)$ & $4 \cdot 29(3)$ & $0.00(0.7)$ & 0.00 & \\
\hline & $15-30$ & $1.51(11)$ & $2 \cdot 50(2)$ & $1.25(1)$ & 0.02 & \\
\hline & $20-35$ & 1.55 (11) & $2 \cdot 22(2)$ & $1.25(1)$ & 0.00 & \\
\hline & $25-40$ & 1.57 (11) & $2.00(2)$ & $1.25(1)$ & 0.01 & \\
\hline & $30-45$ & 1.55 (11) & $1 \cdot 11(1)$ & $2.50(2)$ & $0 \cdot 16$ & \\
\hline & $35-50$ & $1.51(11)$ & $0.00(0.8)$ & $4 \cdot 29(3)$ & $1 \cdot 14$ & \\
\hline \multirow{11}{*}{ Lung: } & $40+$ & $1 \cdot 31(10)$ & $0.00(0.6)$ & $7 \cdot 14(4)$ & $6 \cdot 90$ & \\
\hline & All & $1.01(11)$ & $1.68(4)$ & $1 \cdot 27(4)$ & 0.33 & 0.57 \\
\hline & $0-15$ & $1.24(18)$ & 0.88 (1) & $0.00(0.8)$ & 1.05 & \\
\hline & $5-20$ & $1.07(15)$ & $3 \cdot 23(4)$ & $0.00(1 \cdot 2)$ & 0.01 & \\
\hline & $10-25$ & $1 \cdot 10(15)$ & $2 \cdot 17(3)$ & $0.74(1)$ & 0.01 & \\
\hline & $15-30$ & $1 \cdot 12(15)$ & $1.27(2)$ & $1.39(2)$ & $0 \cdot 10$ & \\
\hline & $20-35$ & $1.14(15)$ & $1.71(3)$ & $0.68(1)$ & 0.02 & \\
\hline & $25-40$ & $1.07(14)$ & $1 \cdot 12(2)$ & $2.00(3)$ & 0.82 & \\
\hline & $30-45$ & 0.98 (13) & $1.78(3)$ & $2.07(3)$ & 1.89 & \\
\hline & $35-50$ & 0.95 (13) & 2.07 (3) & $2 \cdot 40$ (3) & 3.08 & \\
\hline & $40+$ & $1.11(16)$ & $1.83(2)$ & $1 \cdot 14(1)$ & $0 \cdot 11$ & \\
\hline Kidney: & All & $1.63(5)$ & $0.00(0.7)$ & $1 \cdot 15(1)$ & $0 \cdot 34$ & 0.56 \\
\hline Prostate: & All & $0.65(11)$ & $0 \cdot 29(1)$ & $1.42(7)$ & $2 \cdot 04$ & 0.15 \\
\hline
\end{tabular}

Expected numbers are in italics if SIR $=0.00$.

not calculated for the time window analyses. The data were analysed with the program package "epicure". ${ }^{10}$

\section{Results}

The cohort contributed 32816 person-years of observation. During the observation period from 1953 to 1991 , there were 552 deaths in the cohort compared with 559.9 expected, and 210 cancer cases against $188 \cdot 7$ expected. Analysis by cumulative employment (table 2 ) uncovered an excess of cancer cases (90 observed; $\operatorname{SIR}=1.5, \mathrm{P}<0.01$ ) among workers with less than three years of employment. This was due to more cases than expected of cancers of the lung (SIR $=2.65, \mathrm{P}<0.01$ ), skin $(\mathrm{SIR}=3.09, \mathrm{P}<0.05)$, stomach, and prostate. Among men employed for at least three years there were 120 cancer cases against $129 \cdot 7$ expected, and only bladder cancer showed a notable excess (SIR $=1.58)$. As the cancer morbidity pattern among short

Table 4 SIRs for selected cancers in 1953-91 among 694 aluminium smelter workers with at least three years employment, by cumulative exposure to asbestos, pot emissions, heat stress, and magnetic fields

\begin{tabular}{|c|c|c|c|c|c|c|}
\hline \multirow[b]{2}{*}{ Cancer site } & \multirow{2}{*}{$\begin{array}{l}\text { Time window } \\
\text { for exposure } \\
\text { before observation } \\
(y)\end{array}$} & \multicolumn{3}{|c|}{ Cumulative exposure (intensity-y) } & \multirow{2}{*}{$\begin{array}{l}\text { Poisson } \\
\text { trend } \\
\text { statistic } \\
\left(\chi^{2}\right)\end{array}$} & \multirow{2}{*}{$\begin{array}{l}\text { Pvalue } \\
\text { for } \\
\text { trend }\end{array}$} \\
\hline & & $\operatorname{SIR}(n)$ & $\operatorname{SIR}(n)$ & $\operatorname{SIR}(n)$ & & \\
\hline & & \multicolumn{3}{|l|}{ Heat stress } & & \multirow[b]{2}{*}{$0 \cdot 18$} \\
\hline Kidney: & $\begin{array}{l}\text { All } \\
0-15 \\
5-20 \\
10-25 \\
15-30 \\
20-35 \\
25-40 \\
30-45 \\
35-50 \\
40+\end{array}$ & $\begin{array}{l}0 \\
0.63(1) \\
1.08(4) \\
1.18(4) \\
0.95(3) \\
0.67(2) \\
0.71(2) \\
0.74(2) \\
0.73(2) \\
1.02(3) \\
1.23(4)\end{array}$ & $\begin{array}{l}<4 \cdot 5 \\
0 \cdot 81(1) \\
0 \cdot 00(0 \cdot 6) \\
0 \cdot 00(0 \cdot 7) \\
2 \cdot 53(2) \\
2 \cdot 17(2) \\
0 \cdot 96(1) \\
0 \cdot 87(1) \\
0 \cdot 86(1) \\
1.90(2) \\
2 \cdot 22(2)\end{array}$ & $\begin{array}{l}\geqslant 4 \cdot 5 \\
2 \cdot 30(4) \\
6 \cdot 06(2) \\
4 \cdot 08(2) \\
1 \cdot 59(1) \\
2.90(2) \\
4 \cdot 17(3) \\
4 \cdot 11(3) \\
4 \cdot 23(3) \\
1.67(1) \\
0.00(0 \cdot 5)\end{array}$ & $\begin{array}{l}1.82 \\
2.78 \\
1.20 \\
0.56 \\
2.71 \\
4 \cdot 19 \\
3.83 \\
3.97 \\
0.37 \\
0.5\end{array}$ & \\
\hline \multirow[t]{2}{*}{ Bladder } & All & $2 \cdot 24(7)$ & $1 \cdot 28(3)$ & $1 \cdot 19(4)$ & $1 \cdot 10$ & 0.29 \\
\hline & & \multicolumn{3}{|l|}{ Asbestos } & & \\
\hline \multirow[t]{2}{*}{ Lung } & All & $\begin{array}{l}0 \\
1 \cdot 28(15)\end{array}$ & $\begin{array}{l}<0.5 \\
0.56(1)\end{array}$ & $\begin{array}{l}\geqslant 0.5 \\
0.88(3)\end{array}$ & 0.57 & $0 \cdot 45$ \\
\hline & & \multicolumn{3}{|c|}{ Pot emissions } & & \\
\hline \multirow[t]{2}{*}{$\begin{array}{l}\text { Pancreas } \\
\text { Lung }\end{array}$} & $\begin{array}{l}\text { All } \\
\text { All }\end{array}$ & $\begin{array}{l}0 \\
0.71(1) \\
1.60(7)\end{array}$ & $\begin{array}{l}<4 \cdot 3 \\
2 \cdot 03(3) \\
0 \cdot 78(4)\end{array}$ & $\begin{array}{l}\geqslant 4 \cdot 3 \\
0 \cdot 00(2 \cdot 1) \\
1 \cdot 16(8)\end{array}$ & $\begin{array}{l}0.84 \\
0 \cdot 30\end{array}$ & $\begin{array}{l}0.36 \\
0.59\end{array}$ \\
\hline & & \multicolumn{3}{|c|}{ Static magnetic fields } & & \\
\hline Nervous system & All & $\begin{array}{l}0 \\
0.00(1.0)\end{array}$ & $\begin{array}{l}<5.5 \\
0.99(1)\end{array}$ & $\begin{array}{l}\geqslant 5 \cdot 5 \\
0 \cdot 85(1)\end{array}$ & $0 \cdot 61$ & $0 \cdot 44$ \\
\hline Haematopoietic tissue & All & $1 \cdot 19(4)$ & $2 \cdot 79(2)$ & $0.85(3)$ & $0 \cdot 21$ & 0.65 \\
\hline
\end{tabular}

Expected numbers are in italics if $\operatorname{SIR}=0 \cdot 00$. 
term workers differed from that of men with longer employment, the two groups were analysed separately.

Tables 3 and 4 show results from the analysis of associations between cumulative exposure and cancer incidence among the 694 men with at least three years' employment. This subcohort contributed 20468 personyears of observation with a mean age at hire of 27 years and a mean time from first employment to the end of follow up of 41 years. A weak association was found between cumulative exposure to heat stress and kidney cancer $(P=0 \cdot 18)$, and between cumulative exposure to coal tar pitch volatiles and bladder cancer $(P=0 \cdot 21)$. The strongest association was between cumulative exposure to tar and prostatic cancer $(P=0 \cdot 15)$, which had not been specified originally as being of interest.

Analysis by cumulative exposure to tar in time windows (table 3 ) showed that incidence of bladder cancer was associated with exposures received more than 40 years before observation. The incidence of lung cancer was most strongly associated with tar exposure received 35-50 years before observation, and that of kidney cancer with exposure to heat stress 20-35 years before observation (table 4).

No association was found between tar and kidney cancer (table 3), asbestos and lung cancer, pot emissions and cancers of the lung and pancreas, heat stress and bladder cancer, or magnetic fields and cancers of the nervous system and haematopoietic tissues (table 4). Time window analysis did not provide any further evidence about associations between these exposures and cancers. Results for static and time-varying fields were similar, and only the first were therefore given in the table.

The excess of lung and bladder cancers in men employed for less than three years was also examined for associations with tar exposure (not shown in tables). The SIR for lung cancer was 1.60 (three cases) in short term workers exposed to tar $v 2.98$ (17 cases; $\mathrm{P}<$ 0.01 ) in unexposed workers, whereas the result for bladder cancer was $2 \cdot 00$ (two cases) in the exposed group and 1.02 (three cases) in the unexposed group. Inclusion of short term workers in the time window analysis weakened the association between tar exposure and lung cancer, but did not influence the strength of the association with bladder cancer.

\section{Discussion}

The main findings in this study are the associations between exposure to coal tar pitch volatiles and cancers of the bladder and lung, and between heat stress and kidney cancer in the subcohort with at least three years' total employment. The increased cancer incidence in short term workers will be discussed in a subsequent paper, together with the mortality experience in this group. ${ }^{17}$

As cancers of the lung and bladder are also associated with tobacco smoking, the potential influence of smoking must be considered. Data on smoking were available from a survey of respiratory disorders in 132 of the 299 smelter workers employed in $1962 . .^{18}$ The mean year of birth in the surveyed group was comparable with that in the present cohort, 1910 to $1915 v 1918$. The expected proportion of smokers was calculated from age specific smoking rates in Norwegian men in $1960 .{ }^{19}$ In the 112 men with at least five years' employment, there were $71 \%$ current smokers $v 65 \%$ expected, whereas $90 \%$ smoked $v$ an expected $68 \%$ in the 20 men employed for less than five years. The average tobacco consumption per smoker was $12 \mathrm{~g} /$ day, which is similar to the national average at the time. The survey data may overestimate the proportion of smokers as 52 of 56 men with respiratory complaints and only 80 of 243 symptom free workers were included.

From these data on smoking, no more than a slight increase in the incidence of lung cancer and an undetectable increase in the incidence of bladder cancer would be expected among men employed for three years or more. One would also expect differences in smoking habits within the cohort to be indiscriminate with respect to exposures and time windows, and such differences cannot therefore explain the associations found.

Some non-differential misclassification of exposures is unavoidable in studies such as the present one, and the extent was probably larger for asbestos than for the other exposures. ${ }^{10}$ Such misclassification will tend to attenuate a true dose-response relation and may have contributed to the lack of association between asbestos exposure and lung cancer. This result may also be due to the fact that more than $90 \%$ of the men exposed to asbestos had probably been exposed to low levels, and this explanation is supported by the absence of any case of mesothelioma in the cohort.

A consistent finding from previous studies is the association between exposure to coal tar pitch volatiles in Söderberg aluminium smelters and bladder cancer. ${ }^{1-4}$ In this type of plant, tar exposure is correlated with exposure to fluorides, which has recently been implicated as a potential bladder carcinogen. ${ }^{20}$ In our study tar and fluoride exposures were negatively correlated, ${ }^{10}$ and our results therefore support earlier findings that the increased risk of bladder cancer in aluminium smelter workers has primarily been associated with exposure to tar.

Our results for lung cancer support previous findings of an association between exposure to tar and lung cancer reported by $\mathrm{Gibbs}^{2}$ and Armstrong et $a l^{5}$ from studies of Canadian aluminium workers. The finding of an association between tar exposure and prostatic cancer was unexpected and may be due to chance, particularly in light of the absence of cases in the low tar exposure stratum. A slightly raised mortality from this cancer has earlier been reported in anode factory workers in the United States aluminium industry, ${ }^{6}$ but not in Canadian aluminium workers. ${ }^{24}$ No previous study included any analysis of incidence of prostatic cancer by cumulative employment or exposure.

The association between exposure to heat 
stress and kidney cancer could be a chance finding, but this result may be of interest as heat stress in potrooms may cause dehydration, ${ }^{21}$ which possibly may lead to prolonged retention of concentrated urine and an increased tissue dose of carcinogens in the urinary tract. ${ }^{22}$ Increased risk of kidney cancer has been reported from previous studies of workers in aluminium smelters ${ }^{27}$ and other hot environments such as foundries and coke ovens. ${ }^{23}$ Like other investigators, ${ }^{27}$ we found no association between tar exposure and kidney cancer. Five of the six kidney cancers were renal cell neoplasms that are thought to have a different aetiology from that of bladder cancer. ${ }^{24}$

No association was found between exposure to pot emissions and pancreatic cancer, nor between magnetic fields and cancers of the nervous system or haematopoietic tissue. The observed and expected number of cases was small, however, and the study's power to detect an association was therefore limited.

Results from the time window analysis add suggestive information about the temporal relation between exposure to coal tar pitch volatiles and the risk of bladder and lung cancer. In this type of analysis, the time window that yields the strongest association is the one that indicates the most appropriate assumption about the empirical induction period. ${ }^{12}$ Although the small number of cases precludes any firm conclusion, the present results may suggest that the aetiologically relevant exposures have been followed by a latency period of 30-40 years during which further exposure has had little or no effect. This is in line with the suggestive pattern of higher risk of lung cancer from exposures with a latency of 40 years or more noted by Armstrong and coworkers in their study of lung cancer in aluminium smelter workers from Quebec. ${ }^{5}$

As pointed out by Rothman ${ }^{12}$ and Checkoway et $a l,{ }^{14}$ time window analysis may also have a potential for sharpening the analysis of dose-response relations by eliminating aetiologically irrelevant exposures from the dose surrogate. The incidence of bladder and lung cancer found here seemed to be more strongly associated with cumulative exposure to tar calculated within a limited time window than with cumulative exposure throughout employment, possibly because that measure included exposures received outside the induction period. This may suggest that attenuation of these associations could be reduced not only through improving the quality of exposure assessment, but also with use of a dose surrogate that accounts for the time course of induction and latency.

Finally, it should be noted that the temporal relation between tar exposure and the risk of bladder or lung cancer may depend not only on the exposure and disease in question, but also on the dose rate. The duration of the induction and latency periods suggested from this study may therefore be different from those that would be found in populations exposed to higher or lower exposures. Thus it is interesting to note that Spinelli et al were able to show an association between exposure to coal tar pitch volatiles and bladder cancer in workers from a Canadian aluminium smelter that had started production only 31 years before follow up was closed. ${ }^{4}$ Unfortunately, the absence of measurements from the present plant makes it impossible to compare concentrations of coal tar pitch volatiles in the two smelters.

Axel Wannag was responsible for designing the personnel registry that the cohort was constructed from. Oddvar Sandvin designed all programs used with the "epicure" software. We also thank Tor Haldorsen for statistical advice. This work was supported by grants from the Nordic Aluminium Industry's secretariat for Health, Environment, and Safety (AMS) and Secretariat for Health, Environment, and Safety (AMS) and
from the Work Environment Fund of the Confederation of from the Work Environment Fund of the
Norwegian Business and Industry (NHO).

1 Thériault G, Tremblay CG, Cordier S, Gingras S. Bladder cancer in the aluminium industry. Lancet 1984; $\mathbf{i}$ 947-50.

2 Gibbs GW. Mortality of aluminium reduction plant workers, 1950 through 1977. F Occup Med 1985;27:761-70.

3 Armstrong BG, Tremblay CG, Cyr D, Thériault GP. Estimating the relationship between exposure to tar volatiles and the incidence of bladder cancer in aluminium smelter workers. Scand $¥$ Work Environ Health minium smelter

4 Spinelli J, Band PR, Svirchev L, Gallagher RP. Mortality and cancer incidence in aluminium reduction plan workers. F Occup Med 1991;33:1150-5.

5 Armstrong B, Tremblay C, Baris D, Thériault G. Lung cancer mortality and polynuclear aromatic hydrocarbons: a case-cohort study of aluminium production workers in Arvida, Quebec, Canada. Am f Epidemio 1994;139:250-62.

6 Milham S. Mortality in aluminium reduction plant workers. $f$ Occup Med 1991;21:475-80.

7 Rockette HE, Arena VC. Mortality studies of aluminium reduction plant workers: potroom and carbon departreduction plant workers: potroom

8 Andersen A. Cancer mortality and morbidity in Norway. In: Hughes JP, ed. Health protection in primary aluminium production. Vol 2. London, International Primary Aluminium Institute, 1982:49-52.

9 Andersen A, Dahlberg BE, Magnus K, Wannag A. Risk of cancer in the Norwegian aluminium industry. Int $\mathcal{F}$ Cancer 1982;29:295-8.

10 Rønneberg A. Mortality and cancer morbidity in workers from an aluminium smelter with prebaked carbon anodes-part I: exposure assessment. Occup Environ Med 1995;52:242-9.

11 Rønneberg A, Langmark F. Epidemiologic evidence of cancer in aluminium reduction plant workers. $A m \mathcal{f}$ Ind cancer in aluminium red $1992 ; 22: 573-90$.

12 Rothman KJ. Induction and latent periods. Am $\mathcal{F}$ Epidemiol 1981;114:253-9.

13 Langård $S$. The carcinogenicity of chromium compounds in man and animals. In: Burrows D, ed. Chromium: metabolism and toxicity. Boca Raton, Florida: CRC Press, 1983:13-30.

14 Checkoway H, Pearce N, Hickey JLS, Dement JM Latency analysis in occupational epidemiology. Arch Environ Health 1990;45:95-100.

15 Breslow NE, Day NE. Statistical methods in cancer research. Vol II-The design and analysis of cohort studies. Lyon, France: International Agency for Research on Cancer, 1987:96-7.

16 Preston DL, Lubin JH, Pierce DA, McConney ME. Epicure. Seattle, Washington: Hirosoft International Corporation, 1993

17 Rønneberg A. Mortality and cancer morbidity in workers from an aluminium smelter with prebaked carbon anodes - part III: mortality from circulatory and respiratory diseases. Occup Environ Med 1995;52:255-61.

18 Glømme J, Endresen O, Fredhjem E, Lange Andersen $\mathrm{K}$ Industrial hygiene surveys of Den Norske Nitridfabrikk, Eydehamn. Oslo, Norway: Institute of Occupation, Health, 1962. (In Norwegian.)

19 Rønneberg A, Lund KE, Hafstad A. Lifetime smoking habits among Norwegian men and women born between

20 Grandjean P, Olsen JH, Jensen OM, Juel K. Cancer incidence and mortality in workers exposed to fluoride. dence and mortality in workers

21 Rodahl K. Heat stress: Norwegian experience. In: Hughes $\mathrm{JP}$, ed. Health protection in primary aluminium production. Vol 2. London: International Primary Aluminium Institute, 1982:177-84.

22 Parkash O, Kiesswetter $\mathrm{H}$. The role of urine in the etiology of cancer of the urinary bladder. Urol Int 1976;31:343-8.

23 Polynuclear aromatic compounds, Part 3, Industrial exposures in aluminium production, coal gasification, coke production and iron and steel founding. IARC Monog Eval Carcinog Risks Hum 1984;34:101-32.

24 Devesa SS, Silverman DT, McLaughlin JK, Brown CC Connelly RR, Fraumeni JF. Comparison of the descriptive epidemiology of urinary tract cancers. Cancer Causes Control 1990;1:133-41. 